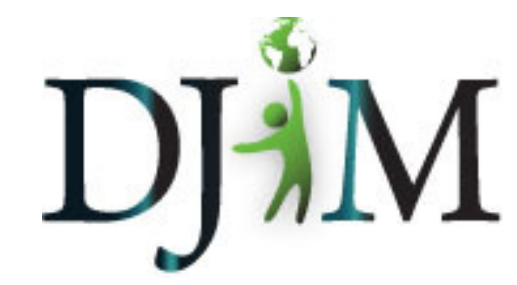

Volume 6 - Spring 2010 djim.management.dal.ca

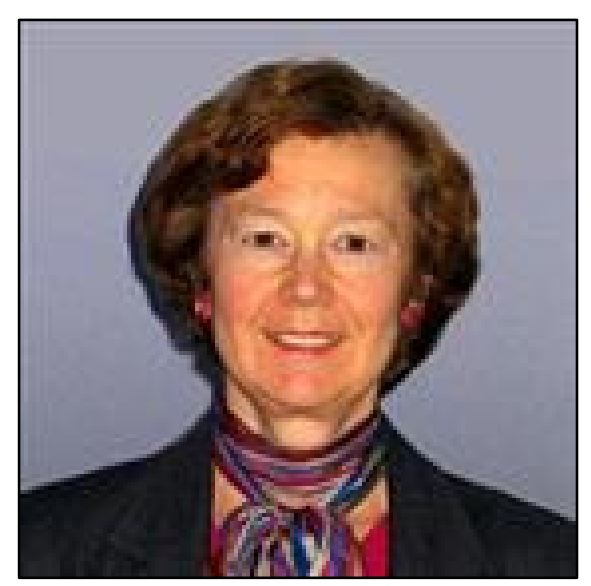

Recently retired from Dalhousie Libraries, Fran Nowakowski shares her reflections on 30 years in the Information profession.

\section{0 years in the business}

When l've been at parties and people have asked me what I do, I have always replied that I am a librarian. I think it is one of the most challenging and rewarding professions to be in. Having been "in the business" for over 30 years, I have seen many changes, some small, some dramatic but they have always provided me with the opportunity to change, grow and develop new skills.

Even before I left Library School, I had begun to get inkling that this profession would be one of continual learning. One of the last projects I did at UBC Library School was to run a program with a batch of punched cards. That was the one and only time because desktop computers were already on their way in. My summer job in a public library did have an automated circulation system but it still required the hand sorting of the date due cards with a rather alarming looking metal poker.

However, when I started at Dalhousie in 1981, the card catalogue was still the primary access point for the collection and Miss Ruth Cordy was the Queen of the card catalogue making sure that we all filed our cards as accurately as possible. I still remember having to put a red flag behind the cards I filed so that she could come along behind and check to make sure I got it right.

In 1982 we got our first computer in the office and it was shared by all of the librarians. At the same time, we began to offer database searching via Dialog as a service. This was exciting but also very stressful as the users actually had to pay for the search results. Every second you spent online and every mistake you made cost money - talk about stress! Still, it was a definite improvement on the time consuming process of examining numerous volumes of periodical indexes.

Three years later, we moved to our first online catalogue GEAC. As clumsy as it was, what a revelation! You could actually get a list of all of the books on a subject published in the last 5 
years instead of having to go through every card in a subject category to find what you wanted. Database searching progressed as well. Huge towers of CD's gave the user the power to do their own searching instead of requiring librarian mediation.

The early 90's is when change really went into high gear. This wonderful new way of communicating called email was introduced. We were all quite thrilled with the concept of instant contact. Little did we know how completely it would take over our lives. At the same time, we began to experiment with something called the internet which actually provided information on all kinds of things using a hyper linked menu interface called Gopher and a search function called Veronica (cartoon characters of the day for you youngsters).

As if that wasn't enough, along comes the biggest change of all - the World Wide Web. The instant access to information, the graphics, the interactivity, the connectivity - wow! It was exciting and challenging, learning how to provide access to our services in a visual way. At this point I will say that most of the time, we had to learn these new tools through experimentation and by looking at how other libraries were handling it. Knowing how to teach ourselves was a very important skill.

Of course, apart from teaching ourselves, we also had to teach our students how to use our resources efficiently and effectively. There have always been new tools to use as the technology develops.

I started making instructional handouts by photocopying, cutting and pasting, literally with scissors and tape. Then in 1987 there was the revolutionary idea that students didn't have to wait for a physical tour, they could do it themselves with a slide tape tour: then 10 years later, our first virtual tour.

What really appealed to me though was finding ways to deliver instruction any time anywhere and that journey took me through many different types of instructional design software Authorware, Lectora and most recently Camtasia. Add into that mix, Photoshop for graphics and Audacity for audio and it was a particularly creative aspect of my work. I am not sure how many online tutorials I have created over the years but I would say well over 100 .

I don't believe that this amount of change is unusual for our profession. It's a hallmark and I am sure will continue in the future. We are always looking for new ways to reach our users, whether we develop them ourselves or take advantage of the creativity of others. If you like order, stability and permanence, then don't become a librarian.

\section{Fran Nowakowski}

former Information Literacy Coordinator

Dalhousie University Libraries (retired) 